\title{
NADH-oxidase, NADPH-oxidase and myeloperoxidase activity of visceral leishmaniasis patients
}

\author{
PROMOD KUMAR, KALPANA PAI*, HAUSHILA P. PANDEY and SHYAM SUNDAR* \\ Department of Biochemistry, Faculty of Science, Banaras Hindu University and *Department of Medicine, \\ Institute of Medical Sciences, Institute of Medical Sciences, Banaras Hindu University, Varanasi- 221005, India
}

\begin{abstract}
It is believed that the enhanced capability of activated macrophages to resist infection is related to the remarkable increase in the production of oxygen metabolites in response to phagocytosis. Both the production of $\mathrm{H}_{2} \mathrm{O}_{2}$ and the oxidation of $\mathrm{NAD}(\mathrm{P}) \mathrm{H}$ are directly dependent upon NAD(P)H-oxidase. It has been established that the respiratory burst is due to activation of $\mathrm{NAD}(\mathrm{P}) \mathrm{H}$-oxidase localised in the plasmalemma. Myeloperoxidase is believed to be involved in augmenting the cytotoxic activity of $\mathrm{H}_{2} \mathrm{O}_{2}$. Low NADHoxidase, NADPH-oxidase and myeloperoxidase activity were observed in monocytes of patients with active visceral leishmaniasis as compared with healthy controls. These results suggest that low NADH-oxidase, NADPH-oxidase and myeloperoxidase activities may account for persistence of Leishmania parasites in visceral leishmaniasis.
\end{abstract}

\section{Introduction}

Visceral leishmaniasis (VL) or kala-azar is caused by Leishmania donovani, an obligate intracellular protozoan that parasitises tissue macrophages. Intramacrophage infection by $L$. donovani results in potentially fatal visceral infections in man and the elimination of Leishmania parasites by the macrophage depends upon the mounting of an effective cell-mediated immune response by the mammalian host [1].

The diseases caused by all species of the Leishmania genus are determined by the fact that these parasites multiply and survive in the microbicidal environment of mononuclear phagocytes [2]. This survival has to be seen in the context that promastigotes of Leishmania are destroyed in vitro by the metabolites of the oxidative burst, hydrogen peroxide $\left(\mathrm{H}_{2} \mathrm{O}_{2}\right)$ and superoxide anion $\left(\mathrm{O}_{2}{ }^{-}\right)$[3] with $\mathrm{H}_{2} \mathrm{O}_{2}$ being more effective than $\mathrm{O}_{2}{ }^{-}$. The respiratory burst is due to increased activation of $\mathrm{NAD}(\mathrm{P}) \mathrm{H}$-oxidase localised in the plasmalemma [4]. The generation of reactive oxidative species (ROIs) is associated with production of certain oxygen metabolites, which is linked to induction of cellular damage, microbicidal activity and the regula-

Received 6 Feb. 2001; revised version accepted 23 May 2002.

Corresponding author: Professor S. Sundar (e-mail: shyam_vns@satyam.net.in). tion of the activity of natural killer cells, polymorphonuclear leucocytes (PMNLs) and monocytes [5]. The conversion of oxygen to microbicidal product is mediated by a plasma membrane-associated enzymes or enzyme system.

Myeloperoxidase (MPO; $\mathrm{H}_{2} \mathrm{O}_{2}$ oxidoreductase) is an enzyme found in the azurophilic granules of mammalian neutrophils and also identified in human monocytes. PMNLs employ a system comprised of MPO, $\mathrm{H}_{2} \mathrm{O}_{2}$ and oxidisable halide co-factor to kill a variety of micro-organisms [6]. MPO is believed to be involved in augmenting the cytotoxic activity of $\mathrm{H}_{2} \mathrm{O}_{2}$ and $\mathrm{O}_{2}{ }^{-}$. Klebenoff [6] has demonstrated that, during endocytosis, MPO is released into the phagosomes as a result of fusion of the phagosome membrane with the azurophil granules. Extracellular release of granule components occurs upon contact of the PMNLs with a large membrane or membrane-like surface. Therefore, NADH-oxidase, NADPH-oxidase and MPO activity were examined in monocytes from patients with active VL.

\section{Materials and methods}

\section{Reagents}

All reagents were prepared in quartz distilled water. Ficoll-Hypaque (Lymphoprep) was obtained from Nycomed Pharma, Norway. RPMI 1640, Hanks's 
Balanced Salts Solution (HBSS), fetal calf serum (FCS) and other reagents were purchased from Sigma. Culture plates were purchased from A/S Nunc, Denmark. NADH, NAD(P)H, SDS, OPD, DMSO and $\mathrm{H}_{2} \mathrm{O}_{2}$ were purchased from Hi Media, India.

\section{Blood samples}

Blood samples of 15 patients with active VL and five endemic area controls were collected from the Kalaazar Medical Research Centre, Muzaffarpur, Bihar. Blood samples of five healthy controls from nonendemic areas were collected from the Institute of Medical Sciences, Banaras Hindu University, Varanasi, Uttar Pradesh.

\section{Isolation of monocytes from peripheral blood mononuclear cells}

Human peripheral blood mononuclear cells (PBMC) were isolated from heparinised blood by the FicollHypaque density gradient method [7] with centrifugation at $2200 \mathrm{rpm}$ for $25 \mathrm{~min}$. PBMC were resuspended in RPMI-1640 supplemented with heat-inactivated FCS $10 \%$, gentamicin $20 \mathrm{mg} / \mathrm{L}$, streptomycin $100 \mathrm{mg} / \mathrm{L}$ and penicillin $100 \mathrm{mg} / \mathrm{L}$. Monocytes $\left(2 \times 10^{5}\right.$ cells/ well) were obtained by adherence for $2 \mathrm{~h}$ at $37^{\circ} \mathrm{C}$ in tissue-culture plates in a $\mathrm{CO}_{2}$ incubator $\left(\mathrm{CO}_{2} 5 \%\right.$, humidity $95 \%$ ).

\section{Assay for NADH- and NADPH-oxidase [8]}

Monocytes were washed with fresh culture medium and the cells were lysed in $2.0 \mathrm{ml}$ of SDS $0.25 \%$ in distilled water; $0.5 \mathrm{ml}$ of this cell lysate was added to a tube containing $2.5 \mathrm{ml}$ of $0.1 \mathrm{M}$ sodium phosphate buffer, $\mathrm{pH}$ 7.5. The $\mathrm{OD}_{340}$ of the sample was determined for NADPH- and NADH-oxidase activity. For preparing standards, accurately weighed amounts of $\beta$-nicotinamide adenine dinucleotide phosphate (NADPH) and nicotinamide adenine dinucleotide (NADH) $(2 \mathrm{mg}$ of each) were dissolved in $5 \mathrm{ml}$ of phosphate buffer, $\mathrm{pH}$ 7.5. The $\mathrm{OD}_{340}$ of each of several dilutions of this stock solution was read against the buffer.

A calibration curve was plotted and the $\mathrm{OD}_{340}$ values of samples were compared with the standard $\mathrm{OD}_{340}$ of the NADH-oxidase and NADPH-oxidase. The increase or decrease in the $\mathrm{OD}_{340}$ was directly related to the increase or decrease in the enzyme activity. The data are represented as increase or decrease in $\mathrm{OD}_{340}$.

\section{Assay for $M P O$}

MPO activity of monocytes was assessed in the cell lysates by the following method [8]. Monocytes were lysed in Triton X-100 $0.05 \%$ and were kept frozen at $-70^{\circ} \mathrm{C}$ until use. The substrate cocktail contained $5 \mathrm{ml}$ of $0.1 \mathrm{M}$ citrate buffer ( $\mathrm{pH} 5.5$ ), $32 \mu \mathrm{l}$ of Triton X-100 $20 \%, 50 \mu \mathrm{l}$ of $82.4 \mathrm{mM} O$-Dianisidine or OPD in dimethyl sulphoxide $(20.1 \mathrm{mg} / \mathrm{ml}$ in DMSO) and $20 \mu \mathrm{l}$ of $26.4 \mathrm{mM} \mathrm{H}_{2} \mathrm{O}_{2}$. To $0.5 \mathrm{ml}$ of cell lysate, $0.7 \mathrm{ml}$ of $0.1 \mathrm{M}$ citrate buffer ( $\mathrm{pH} 5.5$ ) was added. Then $4.8 \mathrm{ml}$ of the above assay mixture was again added. The mixture was kept at room temperature for $1 \mathrm{~h}$ and the $\mathrm{OD}_{450}$ was measured.

Enzyme activity at room temperature $=$

$$
\frac{\mathrm{OD}^{\mathrm{E}}{ }_{450}-\mathrm{OD}^{\mathrm{B}}{ }_{450} \text { units } / \mathrm{min} / \mathrm{ml} \text { of cell lysate }}{\text { time }(\mathrm{min}) \times \text { volume of samples }(\mathrm{ml})}
$$

where $\mathrm{OD}_{450}^{\mathrm{E}}=\mathrm{OD}_{450}$ of experimental sample and $\mathrm{OD}_{450}^{\mathrm{B}}=\mathrm{OD}_{450}$ of blank.

\section{Results}

\section{Study population}

The clinical and laboratory features of the 15 patients on admission are summarised in Table 1.

\section{NADH-oxidase activity in monocytes}

Monocyte lysates were assayed for their NADH-oxidase activity against the standards. The increase or decrease in $\mathrm{OD}_{340}$ directly shows increased or decreased NADH-oxidase activity. Monocytes from healthy controls from endemic and non-endemic regions showed significantly greater NADH-oxidase activity than those from patients with active VL (Table 2).

\section{NADPH-oxidase activity in monocytes}

Monocyte lysates were assayed for their NADPHoxidase activity against the standards. The increase or decrease in $\mathrm{OD}_{340}$ directly shows increased or decreased NADPH-oxidase activity. Monocytes from healthy controls from endemic and non-endemic regions showed significantly higher NADPH-oxidase activity than those from patients with active VL (Table 2).

\section{Myeloperoxidase activity in monocytes}

Monocytes isolated from healthy endemic and nonendemic controls showed significantly higher myeloperoxidase activity than those from active VL patients (Table 2).

\section{Discussion}

It is believed that the enhanced capability of activated macrophages to resist infection [9] is related to the remarkable increase in the production of oxygen metabolites in response to phagocytosis. It is further believed that the greater oxidative metabolic responses of the activated macrophages could play a marked role in the accelerated capacity to affect cell-mediated immunity. 
Table 1. Clinical and laboratory features of patients with visceral leishmaniasis

\begin{tabular}{lccc}
\hline & & \multicolumn{2}{c}{ Controls from } \\
\cline { 3 - 4 } Criteria & VL patients & endemic region & $\begin{array}{c}\text { non-endemic } \\
\text { region }\end{array}$ \\
\hline Number of patients & 15 & 5 & 5 \\
Age (years) & $21.1(3.8)^{*}$ & $25.6(3.1)$ & $27.2(3.4)$ \\
Duration of illness (months) & $4.3(0.3)$ & $\ldots$ & $\ldots$ \\
Weight $(\mathrm{kg})$ & $43.3(5.7)$ & $52.8(5.9)$ & $\ldots$ \\
Karnofsky score ${ }^{\dagger}$ & $74.0(1.6)$ & $\ldots$ & $\ldots$ \\
Spleen size $(\mathrm{cm})$ & $8.3(1.3)$ & $\ldots .5)$ \\
Splenic aspirate score & $2.2(0.3)$ & $9.1(1.1)$ & $\ldots$ \\
WBC count $\left(\times 10^{3} / \mathrm{mm}^{3}\right)$ & $3.6(0.88)$ & $13.6(1.5)$ & $14.1(1.2)$ \\
Haemoglobin $(\mathrm{g} / \mathrm{dL})$ & $8.9(0.5)$ & $175.0(20.9)$ & $184.0(21.1)$ \\
Platelet count $\left(\times 10^{3} / \mathrm{mm}^{3}\right)$ & $0.7(0.1)$ & & $\ldots$
\end{tabular}

${ }^{*}$ Results are means and (SD).

${ }^{\dagger}$ Karnofsky performance scale:

Able to carry on normal activity: $\quad 100 \quad$ Normal, no complaints, no evidence of no special care is needed. disease.

90 Able to carry on normal activity, minor signs or symptoms of disease.

80 Normal activity with effort, some signs or symptoms of disease.

Unable to work, able to live at home and care for most personal needs, a varying amount of assistance is needed.

Unable to carry on normal activity or to do active work.

Table 2. In-vitro NADH-oxidase, NADPH-oxidase and MPO activities in monocytes from patients with active VL and healthy controls

\begin{tabular}{lccc}
\hline & $\begin{array}{c}\text { Mean (SD) NADH- } \\
\text { oxidase activity } \\
\left(\mathrm{OD}_{340}\right)\end{array}$ & $\begin{array}{c}\text { Mean (SD) NADPH- } \\
\text { oxidase activity } \\
\left(\mathrm{OD}_{340}\right)\end{array}$ & $\begin{array}{c}\text { Mean (SD) } \\
\text { MPO activity } \\
\text { (units } / \mathrm{min} / \mathrm{ml})\end{array}$ \\
\hline Acute VL patients (15) & $7.86(0.632)^{*}$ & $10.66(0.665)^{* *}$ & $0.758(0.047) \times 10^{-4 * *}$ \\
Uninfected (10) & $9.15(0.105)$ & $12.33(0.359)$ & $1.23(0.042) \times 10^{-4}$ \\
\hline
\end{tabular}

* Significantly decreased versus uninfected controls, $\mathrm{p}<0.01$.

$* *$ Significantly decreased over uninfected controls, p $<0.001$.

In the present study, decreased NADH-oxidase and NADPH-oxidase activity was observed in monocytes of patients with active VL than in controls. It can be suggested that down-regulated activity of NADHoxidase and NADPH-oxidase may account for the persistence of Leishmania parasites in patients. As ROIs, a result of respiratory burst activity, are essential for anti-leishmanial activity by macrophages, both the production of $\mathrm{H}_{2} \mathrm{O}_{2}$ and oxidation of NADPH are directly dependent upon NADPH-oxidase [10].

In an earlier study, $\mathrm{H}_{2} \mathrm{O}_{2}, \mathrm{O}_{2}{ }^{-}$and IFN- $\gamma$ production by monocytes from VL patients were examined [11]. $\mathrm{H}_{2} \mathrm{O}_{2}, \mathrm{O}_{2}{ }^{-}$and IFN- $\gamma$ production by cultured monocytes from patients with active VL were significantly lower than in healthy controls. In contrast, nitrite levels in the supernates of monocyte cultures of VL patients were similar to those of healthy controls and increased significantly during antileishmanial therapy. On day 20 of treatment, a significant increase in the release of $\mathrm{H}_{2} \mathrm{O}_{2}, \mathrm{O}_{2}^{-}$and IFN- $\gamma$ was observed. However, at follow-up, 4 months after the end of treatment, the production $\mathrm{H}_{2} \mathrm{O}_{2}, \mathrm{O}_{2}{ }^{-}$, IFN- $\gamma$ and nitrite had declined significantly. Thus, the impairment in $\mathrm{H}_{2} \mathrm{O}_{2}$ and $\mathrm{O}_{2}{ }^{-}$ production suggests that down-regulation of these mediators may be involved in the reduced killing of parasites by monocytes of patients with active VL. Furthermore, it suggests that an immune-based mechanism is involved in successful drug therapy [11].

It has been established that the respiratory burst is due to activation of $\mathrm{NAD}(\mathrm{P}) \mathrm{H}$-oxidase localised in the plasmalemma. The formation of $\mathrm{O}_{2}{ }^{-}$radicals as well as other active forms of oxygen represents a major anti-infection defence by phagocytosing cells. The failure of phagocytes from patients with chronic granulomatous disease (CGD) to kill intracellular amastigotes even after treatment with IFN- $\gamma$ indicates the important role of the oxidative burst for this function [12]. Murray and Nathan [13] determined the relative contribution of ROIs versus reactive nitrogen intermediates (RNI) in respiratory burst-deficient gp91(phox)1-)X-linked CGD and concluded that (a) ROI and RNI probably act together in the early stages 
of infection and (b) RNI alone are necessary and sufficient for the eventual control of VL infection. The same cannot be said in the case of man, as scant information is available on role(s) of $\mathrm{NO}$ in the pathology of VL.

The role of ROIs in the phagocytic functions of Kupffer cells (KCs) and Candida albicans activity was studied by Potoka et al. [14] Their study indicated that ROIs generated by both NADPH-oxidase- and xanthine oxidase-dependent pathways are important in killing of C. parapsilosis by KCs [14]. The neutrophil respiratory burst oxidase is a multi-component activatable enzyme comprising one of the major phagocyte antimicrobial systems. In the genetic disorder CGD, absent oxidase function is associated with recurrent, severe and often life-threatening infections [15].

Fazal [16] determined the role of ROIs in limiting the growth of intracellular mycobacteria within peripheral blood-derived neutrophils and monocyte-derived macrophages from patients with CGD and normal healthy human volunteers. CGD patients are known to have a hereditary defect in the NADPH-oxidase pathway, resulting in their neutrophils and monocytederived macrophages being unable to generate oxygen radicals which are required to kill intracellular bacteria [17]. The cells were infected with Bacille CalmetteGuérin (BCG) or Mycobacterium avium, and the bacterial growth in each cell type was determined by cfu estimate. The results indicated that there was no demonstrable inhibition in the intracellular mycobacterial growth within neutrophils or macrophages from either CGD patients (deficient in NADPH-oxidase pathway) or normal healthy volunteers. Macrophage treatment with either IFN- $\gamma$ or TNF- $\alpha$ had no effect [16].

Condino-Neto et al. [18] investigated the NADPHoxidase activity, cytochrome b558 content and gene expression of gp91-phox and p47-phox in normal Epstein-Barr virus (EBV)-transformed B lymphocytes and compared them to EBV-transformed B lymphocytes from patients with X-linked CGD, normal peripheral blood neutrophils or mononuclear cells, and the A301 or C8166 lymphoblastoid cell lines. They concluded that NADPH-oxidase activity and cytochrome b558 content correlate with gp91-phox and p47-phox gene expression in EBV-transformed B lymphocytes.

MPO is believed to be involved in augmenting the cytotoxic activity of $\mathrm{H}_{2} \mathrm{O}_{2}$ and $\mathrm{O}_{2}{ }^{-} \cdot \mathrm{H}_{2} \mathrm{O}_{2}$ or other oxygen intermediates may mediate the toxic effects of macrophages, either directly or in combination with MPO. Low MPO activity observed in patients with active VL may contribute to survival of parasites in macrophages. It is well known that one of the biological functions of certain peroxidases is to form a potent cytotoxic compound. For MPO to act in this capacity, i.e., to augment the cytotoxic activity of $\mathrm{H}_{2} \mathrm{O}_{2}$ and $\mathrm{O}_{2}{ }^{-}$, the MPO would have to have increased activity for target cell killing [19].

Rosen and Michel [20] found that neutrophils with an intact MPO antimicrobial system (normal or appropriately supplemented deficient cells) were capable of rapidly suppressing Escherichia coli DNA synthesis, whereas unsupplemented CGD or MPO-deficient cells were far less effective, indicating that the MPO system was active in normal neutrophils. The degree of DNA synthesis inhibition by MPO-sufficient neutrophils could account, in a cell-free system, for most of the observed microbicidal activity. Rapid and extensive inhibition of bacterial DNA synthesis appears to be an indicator of MPO activity in neutrophils [20].

MPO catalyses the reaction of $\mathrm{H}_{2} \mathrm{O}_{2}$ with chloride ion to produce hypochlorous acid $(\mathrm{HOCl})$, which is used for microbial killing by phagocytic cells. Despite the important role of MPO in host defence, MPO deficiency is relatively common in man, and most of these individuals are in good health. Aratani et al. studied mice with no MPO activity in their neutrophils and monocytes. They developed normally, were fertile and showed normal clearance of intraperitoneal Staphylococcus aureus. However, they showed increased susceptibility to pneumonia and death following intratracheal infection with $C$. albicans. Furthermore, the lack of MPO significantly enhanced the dissemination of C. albicans injected intraperitoneally, thereby suggesting that MPO is important for early host defence against fungal infection, and the inability to generate $\mathrm{HOCl}$ cannot be compensated for by other oxygen-dependent systems in vivo in mice. The mutant mice serve as a model for studying pulmonary and systemic candidiasis [21].

The observation that this system is able to generate large IgG aggregates [22] suggests that it could be linked to the activation of phagocytic cells. Duc Dodon et al. [23] reported that hyposialylated $\mathrm{IgG}$, either as monomers or as aggregates, can induce the decrease of intracellular MPO content in human monocytes. Indeed, all the visceralising species of Leishmania are known to stimulate the immunoglobulin-producing $\mathrm{B}$ cells non-specifically to produce antibodies of all classes and subtypes including $\operatorname{IgA}$, IgM, IgG, etc. In contrast, albumin production is reduced and thus the albumin:globulin ratio is reversed and hypergammaglobinaemia is observed [24,25].

While there are some facts known, most of the theories regarding the immunopathogenesis of $\mathrm{VL}$ rely on inferences from human cutaneous leishmaniasis and clues obtained from murine models. No model mimics the various forms of human disease perfectly. However, there are no studies available on the biochemical aspects of respiratory burst activity in VL. To our knowledge, this is the first study that has investigated 
NADH-oxidase, NADPH-oxidase and MPO activity in patients with active VL infections. We conclude that there is a down-regulation of NADH-oxidase, NADPHoxidase and MPO (biochemical parameters of macrophage activation) activity in the pathology of VL infection.

This work was supported by grants from Indo US Vaccine Action Program. P.K. is a recipient of a Senior Research Fellowship from the University Grant Commission, New Delhi.

\section{References}

1. Locksley RM, Lous JA. Immunology of leishmaniasis. Curr Opin Immuol 1992; 4: 413-418.

2. Pearson RD, Wheeler DA Harrison LH, Kay HD. The immunobiology of leishmaniasis. Rev Infect Dis 1983; 5: 907-927.

3. Haidaris CG, Bonaventure PE. A role for oxygen-dependent mechanisms in killing of Leishmania donovani tissue forms by activated macrophages. J Immunol 1982; 129: 850-855.

4. Dewald B, Baggiotini M, Curnutte JT, Babior BM. Subcellular localization of the superoxide-forming enzyme in human neutrophils. J Clin Invest 1979; 63: 21-29.

5. Babior BM. The respiratory burst of phagocytes. $J$ Clin Invest 1984; 73: 599-601.

6. Klebanoff SJ. Myeloperoxidase: contribution to the microbicidal activity of intact leucocytes. Science 1970; 169: 10951097.

7. Boyum A. Isolation of mononuclear cells and granulocytes from human blood. Scand J Clin Lab Invest 1968; 21 Suppl: 77-80.

8. Gupta P. PhD thesis, Banaras Hindu University, Varanasi, India, 1988.

9. Mackeness GB. In: Mudd S (ed) Infectious agents and host reactions. Philadelphia PA, WB Saunders. 1970: 62-67.

10. Badwey JA, Karnovsky ML. Production of superoxide and hydrogen peroxide by an NADH-oxidase in guinea pig polymorphonuclear leukocytes. J Biol Chem 1979; 254: $11530-11537$.

11. Kumar R, Pai K, Sundar S. Reactive oxygen intermediates, nitrite and IFN- $\gamma$ in Indian visceral leishmaniasis. Clin Exp Immunol 2001; 124: 262-265.
12. Passwell JH, Shor R, Smolen J, Jaffe CL. Infection of human monocytes by Leishmania results in a defective oxygen burn. Int J Exp Pathol 1994; 75: 277-284.

13. Murray HW, Nathan CF. Macrophage microbicidal mechanism in vivo: reactive nitrogen versus oxygen intermediates in the killing of intracellular visceral Leishmania donovani. $J$ Exp Med 1999; 189: 741-746.

14. Potoka DA, Takao S, Owaki T, Bulkley GB, Klein AS. Endothelial cells potentiate oxidant-mediated Kupffer cell phagocytic killing. Free Radic Biol Med 1998; 24: 1217-1227.

15. Clark RA. Activation of the neutrophil respiratory burst oxidase. J Infect Dis 1999; 179 Suppl 2: S309-S317.

16. Fazal N. The role of reactive oxygen species (ROS) in the effector mechanisms of human antimycobacterial immunity. Biochem Mol Biol Int 1997; 43: 399-408.

17. Rae J, Newburger PE, Dinauer MC et al. X-linked chronic granulomatous disease: mutations in the CYBB gene encoding the gp91-phox component of respiratory-burst oxidase. $A m \mathrm{~J}$ Hum Genet 1998; 62: 1320-1331.

18. Condino-Neto A, Newburger PE. NADPH oxidase activity and cytochrome b558 content of human Epstein-Barr-virus-transformed B lymphocytes correlate with expression of genes encoding components of the oxidase system. Arch Biochem Biophys 1998; 360: 158-164.

19. Grisham MB, Everse J. The role of pyridine nucleotides in phagocytosis. In: Everse J, Anderson B (eds) The pyridine nucleotide coenzymes. New York, Academic Press. 1982.

20. Rosen H, Michel BR. Redundant contribution of myeloperoxidase-dependent systems to neutrophil-mediated killing of Escherichia coli. Infect Immun 1997; 65: 4173-4178.

21. Aratani Y, Koyama H, Nyui S, Suzuki K, Kura F, Maeda N. Severe impairment in early host defense against Candida albicans in mice deficient in myeloperoxidase. Infect Immun 1999; 67: 1828-1836.

22. Jasin HE. Generation of IgG aggregates by the myeloperoxidase-hydrogen peroxide system. J Immunol 1983; 130: 19181923.

23. Duc Dodon M, Gazzalo L, Quash GA. Cellular myeloperoxidase activity in human monocytes stimulated by hyposialylated immunoglobulins and rheumatoid factors. Immunology 1984; 52: 291-297.

24. Bray RS. Immunodiagnosis of leishmaniasis. In: Cohen S, Sadun EH (eds) Immunology of parasitic infections. Oxford, Blackwell Scientific Publications. 1976: 65-76.

25. Bray RS. Immunodiagnosis of leishmaniasis. In: Chang KP, Bray RS (eds) Leishmaniasis. Amsterdam, Elsevier Science Publishers. 1985: 177-182. 